\title{
Prevalence and incidence of hyperplastic polyps and adenomas in familial colorectal cancer: correlation between the two types of colon polyps
}

\author{
A Liljegren, A Lindblom, S Rotstein, B Nilsson, C Rubio, E Jaramillo
}

See end of article for authors' affiliations

\section{Correspondence to:}

A Lindblom, Department of Molecular Medicine CMM L8-02, Karolinska Hospital S 17176 Stockholm,

Sweden;

annika.lindblom@cmm.ki.se

Accepted for publication 5 March 2003

Background and aims: Colorectal adenomas are recognised as precursors of colorectal carcinomas. The significance of hyperplastic (metaplastic) colorectal polyps is unknown. The relationship between hyperplastic polyps and adenomas, and the prevalence and incidence of these lesions were evaluated in individuals predisposed to familial colorectal cancer.

Methods: A total of 299 individuals participating in our surveillance programme during 1990-2000 were retrospectively evaluated. Subjects were classified into three groups: hereditary non-polyposis syndrome (HNPCC) $(n=108)$, hereditary colorectal cancer (HCRC) $(n=127)$, and individuals with empirical risk estimates - two close relatives (TCR) $(n=64)$. Findings from 780 colonoscopies were evaluated regarding prevalence and incidence of hyperplastic polyps and adenomas. Correlations between hyperplastic polyps and adenomas were calculated by Pearson correlation.

Results: In total, 292 hyperplastic polyps and 186 adenomas were observed in 98 and 90 individuals, respectively. A positive correlation was found between the numbers of hyperplastic polyps and adenomas $(r=0.40 ; p<0.001)$. Correlations between adenomas and hyperplastic polyps were similar in the three groups. The risk of detecting new hyperplastic polyps (odds ratio 5.41) or adenomas (OR $2.56)$ increased significantly when there was a positive finding at first colonoscopy.

Conclusion: Hyperplastic polyps as well as adenomas may identify individuals with a high risk of colorectal cancer. This information is important when these individuals are selected and included in tailored surveillance programmes.

C lorectal adenomas are known to be precursors of sporadic and hereditary colorectal cancer.' ${ }^{1}$ Surveillance programmes including colonoscopy and polypectomy reduce both the incidence and mortality among individuals with hereditary colorectal cancer. ${ }^{2}$ In the general population the most frequently occurring lesion in the colon is the hyperplastic (metaplastic) polyp ${ }^{34}$ and the prevalence in autopsy studies in individuals younger than 50 years of age has been documented as $7-40 \% .^{35}$ In individuals over the age of 50 years, the prevalence of hyperplastic polyps has been found to be $20-40 \%{ }^{35}$ Hyperplastic polyps could act as a marker for future adenomas in the general population ${ }^{67}$ as well as for synchronous or metachronous colorectal neoplasia. ${ }^{8}$ There is much discussion about the significance of these polyps in colorectal carcinogenesis, and it is still not clear if hyperplastic polyps are precursors to adenomas or if they constitute an entity of their own with or without a cancer risk.

Colorectal cancer is the third most common type of malignancy in Sweden, and there is a 5\% lifetime risk of developing colorectal cancer.' Individuals with a family history of colorectal cancer have a risk variability for colorectal cancer of $10-40 \%$, depending on how many relatives and at what age they are diagnosed with colorectal cancer. ${ }^{10}{ }^{11}$ In individuals with known predisposing mutations, the risk could be as high as $100 \%{ }^{12}$

There are several types of hereditary colorectal cancer. During the past 10 years several genes have been identified in syndromes with colorectal cancer. ${ }^{12}$ One is hereditary nonpolyposis colorectal cancer (HNPCC) caused by germline mutations in the DNA mismatch repair genes $h M S H 2,{ }^{13}$ hMLHl, ${ }^{14}$ and sometimes $h M S H 6 .{ }^{15}$ The tumours are often located in the right side of the colon, have a more favourable prognosis than sporadic colorectal cancer and, in particular, tumours associated with germline mutations in $h M L H l$ or
hMSH2 generally show microsatellite instability (MSI). ${ }^{16}$ Another type of hereditary colorectal cancer, not fulfilling the Amsterdam criteria ${ }^{17}$ constitutes families with a late onset of the disease. These families had three or more relatives with colorectal cancer and are likely to segregate unknown predisposing mutations leading to hereditary colorectal cancer (HCRC). These individuals have a similar risk of developing colorectal cancer as individuals with HNPCC. ${ }^{10}{ }^{11}$ In addition, there are individuals with an increased risk of colorectal cancer based on a family history of colorectal cancer. ${ }^{10}{ }^{11}$ Individuals in families defined by two first degree relatives with colorectal cancer, "two close relatives" (TCR), have an estimated risk of $10-20 \%$ based on empirical data. ${ }^{11}$

Over a time period of 10 years, we have provided surveillance for patients with an increased risk of colorectal cancer. In a recent study we reported that this risk population had more adenomas than the general population, and that HNPCC individuals had an earlier onset of adenomas and a faster progression to cancer compared with the two other groups (HCRC and TCR).$^{18}$ The same study also suggested that adenomas in HNPCC were associated with a higher cancer risk than adenomas in HCRC, and particularly in TCR. During the surveillance period we noted that hyperplastic polyps were frequent findings in the subjects under surveillance. A higher prevalence of hyperplastic polyps has previously been found in patients with colorectal carcinoma compared with those without colorectal carcinoma, ${ }^{19}$ suggesting that hyperplastic

Abbreviations: AFAP, attenuated familial adenomatous polyposis; HCRC, hereditary colorectal cancer; HNPCC, hereditary non-polyposis colorectal cancer; MSI, microsatellite instability; OR, odds ratio; TCR, two close relatives with colorectal cancer. 
Table 1 Correlation of adenomas and hyperplastic polyps, including all individuals $(n=299)$

\begin{tabular}{lllll}
\hline Adenoma & $\mathrm{n}$ & $\begin{array}{l}\text { No (\%) individuals with } \\
\text { hyperplastic polyp }\end{array}$ & $\chi^{2}$ & $\mathrm{p}$ Value \\
\hline No & 209 & $43(20.6)$ & 46.9 & $<0.001$ \\
Yes & 90 & $55(61.1)$ & & \\
\hline
\end{tabular}

Table 2 Correlation of adenomas and hyperplastic polyps within the three family groups $(n=299)$

\begin{tabular}{lrlr}
\hline Family type & $\mathbf{n}$ & $r$ & $p$ Value \\
\hline HNPCC & 108 & 0.36 & $<0.001$ \\
HCRC & 127 & 0.45 & $<0.001$ \\
TCR & 64 & 0.30 & 0.016 \\
Overall & 299 & 0.40 & $<0.001$ \\
\hline
\end{tabular}

HNPCC, hereditary non-polyposis colorectal cancer; HCRC hereditary colorectal cancer; TCR, two close relatives with colorectal cancer.

polyps are associated with a risk of colorectal cancer. We have previously shown that adenomas in subjects with an increased risk of colorectal cancer identify risk individuals predisposed to colorectal cancer. ${ }^{18}$ To elucidate the possible relationship between hyperplastic polyps and adenomas in individuals predisposed to colorectal cancer we studied the prevalence and incidence of hyperplastic polyps and adenomas in our surveillance group.

\section{MATERIALS AND METHODS}

\section{Patients}

In total, 299 individuals at risk, participating in the surveillance programme at the Cancer Family Clinic at Karolinska Hospital between January 1990 and December 2000, were retrospectively evaluated. All cancer diagnoses in families were reported by the index patient and were confirmed by medical records, pathological reports, or death certificates. The general screening interval was two years. However, if one or more adenomas were detected and removed, a new colonoscopy was performed the following year according to local procedures. Families were classified according to family type (HNPCC $(n=108)$, HCRC $(n=127)$, or TCR $(\mathrm{n}=64))$ using information on family history, available data on MSI tests in tumours, and mutation screening results of mismatch repair genes in affected members. The HNPCC group consisted of mutation carriers tested positive, and untested individuals belonging to HNPCC families according to Amsterdam criteria I (only colorectal cancer was counted as positive for the purpose of diagnosing a relative as affected) with known or unknown predisposing mutations. The HCRC group consisted of individuals from families with three or more individuals with colorectal cancer diagnosed when over
50 years of age, with MSI negative tumours, and with a negative mismatch repair gene mutation screening. Families fulfilling Amsterdam criteria I, but with tumours negative for MSI and mutation screening negative were also classified as HCRC. The TCR group consisted of families with two first degree relatives affected with colorectal cancer, with MSI negative tumours, and a negative mutation screening.

\section{Cancer tumours in the study population}

In total, there were 24 individuals who had a colorectal cancer before starting surveillance, (20 individuals from the HNPCC group, all positive mutation carriers, two individuals from the HCRC group, and two individuals from the TCR group). Two of the individuals in the HNPCC group developed a metachronous colorectal cancer during surveillance. Two positive mutation carriers had a colorectal cancer diagnosed at first colonoscopy. Distribution of the colorectal cancers among affected family members in the three family types was obtained from an earlier study. ${ }^{18}$ This investigation of all 111 families in the former study displayed 81 HNPCC cancers, 52 HCRC cancers, and 51 TCR cancers. ${ }^{18}$ No information on adenomas or hyperplastic polyps was available in these individuals because most of the individuals were already dead and had not been part of any surveillance programme.

\section{Endoscopy and pathology}

Endoscopy information included the number and distribution of all polyps. The proximal colon included the caecum, the right flexure, the transverse colon, and the left flexure. The distal colon included the colon below the end of the left flexure to the end of the rectum. The same colonoscopist performed almost all colonoscopies using a standard video colonoscope. All polyps were either biopsied or removed endoscopically. Hyperplastic polyps were described as protruding or non-protruding. The endoscopist also reported their size (in $\mathrm{mm}$ ) and the procedures for removal. The same pathologist examined all specimens. Histologically, the polyps were classified as non-neoplastic and neoplastic. A non-neoplastic hyperplastic polyp (metaplastic polyp) was defined as a focus of mucosal hyperplasia. Lieberkühn's crypts showed a sawtooth configuration due to crenated epithelium. Cells were columnar with or without apical mucus vacuoles alternating with large goblet cells. The base of the crypts was lined by regular cells with small round nuclei. Neoplastic polyps were classified as tubular, tubulovillous, villous, or serrated adenomas. A tubular adenoma was defined as an adenoma having $\geqslant 80 \%$ dysplastic epithelium arranged as tubules. A villous adenoma was defined as an adenoma having $>80 \%$ dysplastic epithelium arranged as straight villous fronds. A tubulovillous adenoma was defined as a mixed adenoma with more than $20 \%$ but less than $80 \%$ dysplastic villous formations. ${ }^{20}$ In serrated adenomas the histology displayed an epithelium covering the sides of the crypts of Lieberkühn showing crenated sawtooth-like configurations due to scalloped epithelial infolding. In smaller serrated adenomas, only cells at the lower part of the crypts were dysplastic but in larger adenomas the dysplastic epithelium was present in the upper part of the

\begin{tabular}{|c|c|c|c|c|c|c|}
\hline $\begin{array}{l}\text { Adenoma or } \\
\text { hyperplastic } \\
\text { polyp at } 1 \mathrm{st} \\
\text { colonoscopy }\end{array}$ & $\mathrm{n}$ & $\begin{array}{l}\text { No (\%) individuals } \\
\text { with adenoma or } \\
\text { hyperplastic polyp } \\
\text { during follow up }\end{array}$ & $\chi^{2}$ & $\mathrm{p}$ Value & $\begin{array}{l}\text { Observation } \\
\text { time }(y)\end{array}$ & $\begin{array}{l}\% \text { corrected for } \\
\text { observation time } \\
(3 \text { y) }\end{array}$ \\
\hline No & 215 & $49(22.8)$ & \multirow{2}{*}{10.70} & \multirow{2}{*}{0.001} & 3.1 & 22.1 \\
\hline Yes & 84 & 35 (41.7) & & & 2.2 & 58.9 \\
\hline
\end{tabular}




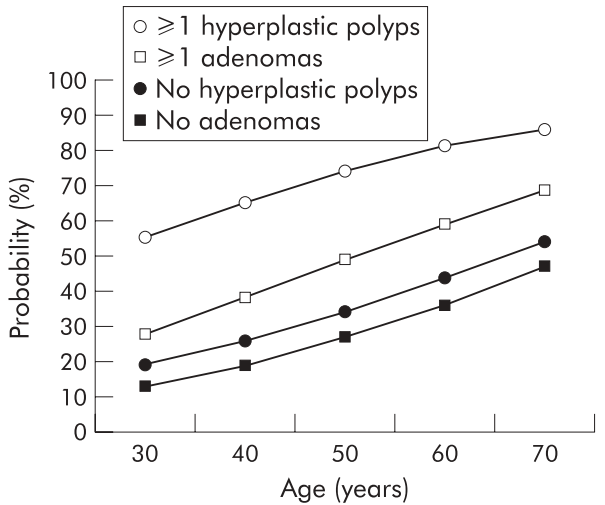

Figure 1 Model based fitted for the probability of detecting a hyperplastic polyp or an adenoma at subsequent colonoscopy (five years) depending on positive or negative findings at the first colonoscopy.

crypts. When serrated fronds were present in $>50 \%$ of dysplastic tissue, the adenoma was classified as serrated. ${ }^{21}$ According to the grade of dysplasia, adenomas were classified as having low grade or high grade dysplasia.

\section{Statistical methods}

Findings from 780 colonoscopies were evaluated with regard to number, size, distribution, prevalence, and incidence of hyperplastic polyps and adenomas. The main functions used for analysing the data were frequency tables, $\chi^{2}$ tables, and linear and logistic regression. The size of the hyperplastic polyps and adenomas and the correlation with recurrence was tested by the exact $\chi^{2}$ test for trend, two sided. Differences in numbers of hyperplastic polyps and adenomas were calculated using ANOVA, post hoc tests, and the $\chi^{2}$ method. Prevalence during follow up was calculated using univariate analyses and multivariate linear regression with the following factors: age at last observation, family classification, and sex.

Incidence (number of hyperplastic polyps and adenomas found during follow up, excluding all findings at first colonoscopy) of hyperplastic polyps and adenomas during follow up was analysed by univariate analyses using the following factors: mean age at first colonoscopy, observation time, hyperplastic polyp or adenoma at first colonoscopy, sex, and family classification. Subsequently, stepwise logistic regression analyses were performed testing the following background factors: a hyperplastic polyp or an adenoma at first colonoscopy, observation time (years), and age at first colonoscopy.

Logistic regression analyses were also used to calculate the probability of detecting a hyperplastic polyp at a following colonoscopy depending on a positive or negative finding at first colonoscopy.

The fitted model for the hyperplastic polyps was:

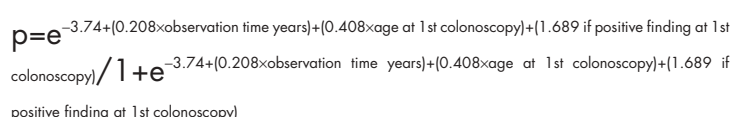

positive finding at lst colonoscopyl

Table 4 Univariate analyses with respect to hyperplastic polyp incidence (no/yes) during follow up

\begin{tabular}{|c|c|c|c|c|}
\hline Categorical factor & $\mathrm{n}$ & $\begin{array}{l}\text { No (\%) individuals with } \\
\text { HP during follow up }\end{array}$ & $\chi^{2}$ & $\mathrm{p}$ Value \\
\hline $\begin{array}{l}\text { HP at } 1 \text { st colonoscopy } \\
\text { No }\end{array}$ & 178 & $47(26.4)$ & \multirow[b]{2}{*}{19.1} & \multirow[b]{2}{*}{$<0.001$} \\
\hline Yes & 30 & $20(66.7)$ & & \\
\hline Sex & & & \multirow{3}{*}{0.1} & \multirow{3}{*}{0.978} \\
\hline Males & 81 & $26(32.1)$ & & \\
\hline $\begin{array}{l}\text { Females } \\
\text { Family classification }\end{array}$ & 127 & 41 (31.3) & & \\
\hline HNPCC & 69 & $18(26.1)$ & \multirow{3}{*}{1.9} & \multirow{3}{*}{0.394} \\
\hline HCRC & 100 & $36(36.0)$ & & \\
\hline TCR & 39 & 13 (33.3) & & \\
\hline HNPCC & 69 & $18(26.1)$ & \multirow{2}{*}{1.8} & \multirow{2}{*}{0.200} \\
\hline HERcrc & 139 & $49(35.3)$ & & \\
\hline
\end{tabular}

Table 5 Univariate analyses with respect to hyperplastic polyp incidence (no/yes) during follow up

\begin{tabular}{|c|c|c|c|c|}
\hline Continous factor & $\mathrm{n}$ & Age at 1 st colonoscopy $(y)^{*}$ & $t$ & $\mathrm{p}$ Value \\
\hline \multicolumn{5}{|l|}{ HP during follow up } \\
\hline No & 141 & $41.9(13.4)$ & \multirow{3}{*}{3.7} & \multirow{3}{*}{$<0.001$} \\
\hline & & & & \\
\hline \multirow[t]{2}{*}{ Yes } & 67 & $48.9(11.7)$ & & \\
\hline & $\mathrm{n}$ & Observation time $(y)^{*}$ & $t$ & $\mathrm{p}$ Value \\
\hline No & 145 & $3.95(1.79)$ & \multirow{3}{*}{1.4} & \multirow{3}{*}{0.178} \\
\hline & & & & \\
\hline Yes & 67 & $4.31(1.85)$ & & \\
\hline
\end{tabular}


Table 6 Stepwise logistic regression analysis with respect to hyperplastic polyp incidence (no/yes) during follow up

\begin{tabular}{lllr}
\hline Factor & OR & $\mathrm{Cl}$ & $\mathrm{p}$ Value \\
\hline HP at 1st colonoscopy & 5.41 & $2.27-12.9$ & $<0.001$ \\
Observation time (y) & 1.23 & $1.03-1.47$ & 0.021 \\
Age 10* & 1.50 & $1.17-1.93$ & 0.001 \\
Constant-3.74 & & & \\
\hline
\end{tabular}

Odds ratio (OR) and $95 \%$ confidence intervals (CI). Competing non-significant factors were sex and family classification: HNPCC and HERcrc.

Age $10^{*}$, age at 1 st colonoscopy with 10 year increment.

HNPCC, hereditary non-polyposis colorectal cancer; HCRC,

hereditary colorectal cancer; TCR, two close relatives with colorectal cancer; HERcrc, HCRC and TCR, HP, hyperplastic polyp.

where $\mathrm{p}=$ probability of one or more hyperplastic polyps during follow up.

The fitted model for the adenomas was:

$$
\begin{aligned}
& p=e^{-4.444+(0.256 \times \text { observation time years })+(0.435 \times a g e \text { at } 15 t \text { colonoscopy })+(0.938 \text { if positive finding at }}
\end{aligned}
$$

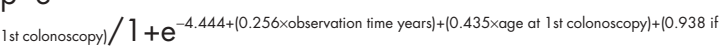

$$
\begin{aligned}
& \text { positive finding at } 1 \text { st colonoscopy }
\end{aligned}
$$

where $\mathrm{p}=$ probability of one or more adenomas during follow up.

The fitted model for hyperplastic polyps and adenomas together during follow up was:

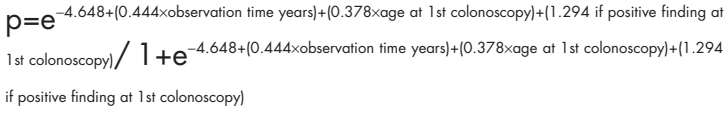

where $\mathrm{p}=$ probability of hyperplastic and/or adenomas during follow up.

The association between hyperplastic polyps and adenomas was calculated by Pearson correlation. The relation of hyperplastic polyps and adenomas at first colonoscopy and during follow up was compared using the Student's $t$ test. Calculations were performed with the statistical package SPSS 11.0 .

\section{Genetic testing}

MSI tests and genetic testing were performed either as part of previous studies or as part of clinical handling and counselling after 1997, and were not part of this study. The MSI test used established methods and criteria. ${ }^{22}{ }^{23}$ Methods used for mutation screening of DNA mismatched repair genes were denatured gradient gel electrophoresis or direct sequencing for $h M L H 1$ and $h M S H 2^{24}$ (and unpublished data), protein truncation test, linkage analysis, and direct sequencing for $h M S H 6,{ }^{25}$ and denaturing high performance liquid chromatography (DHCLP) for $h M L H 3$ (unpublished data). The APC gene was screened using DHCLP (unpublished data).

\section{RESULTS}

In total, 292 hyperplastic polyps and 186 adenomas were observed in 98 and 90 individuals, respectively. Two individuals had colorectal cancer detected at their first colonoscopy,

Table 7 Univariate analyses with respect to adenoma incidence (no/yes) during follow up

\begin{tabular}{|c|c|c|c|c|}
\hline Categorical factor & $\mathrm{n}$ & $\begin{array}{l}\text { No (\%) individuals with } \\
\text { adenomas during follow up }\end{array}$ & $\chi^{2}$ & $\mathrm{p}$ Value \\
\hline \multicolumn{5}{|c|}{ Adenoma at 1 st colonoscopy } \\
\hline No & 175 & $35(20.0)$ & \multirow{3}{*}{7.8} & \multirow{3}{*}{0.005} \\
\hline & & & & \\
\hline Yes & 33 & $14(42.4)$ & & \\
\hline \multicolumn{5}{|l|}{ Sex } \\
\hline Males & 81 & $17(21.0)$ & \multirow{3}{*}{0.5} & \multirow{3}{*}{0.508} \\
\hline & & & & \\
\hline Females & 127 & $32(25.2)$ & & \\
\hline \multicolumn{5}{|l|}{ Family classification } \\
\hline HNPCC & 69 & $13(18.8)$ & \multirow{3}{*}{1.4} & \multirow{3}{*}{0.488} \\
\hline HCRC & 100 & $25(25.0)$ & & \\
\hline TCR & 39 & $11(28.2)$ & & \\
\hline \multirow[t]{2}{*}{ HNPCC } & 69 & $13(18.8)$ & \multirow{3}{*}{1.3} & \multirow{3}{*}{0.300} \\
\hline & & & & \\
\hline HERcrc & 139 & $36(25.9)$ & & \\
\hline
\end{tabular}

Table 8 Univariate analyses with respect to adenoma incidence (no/yes) during follow up

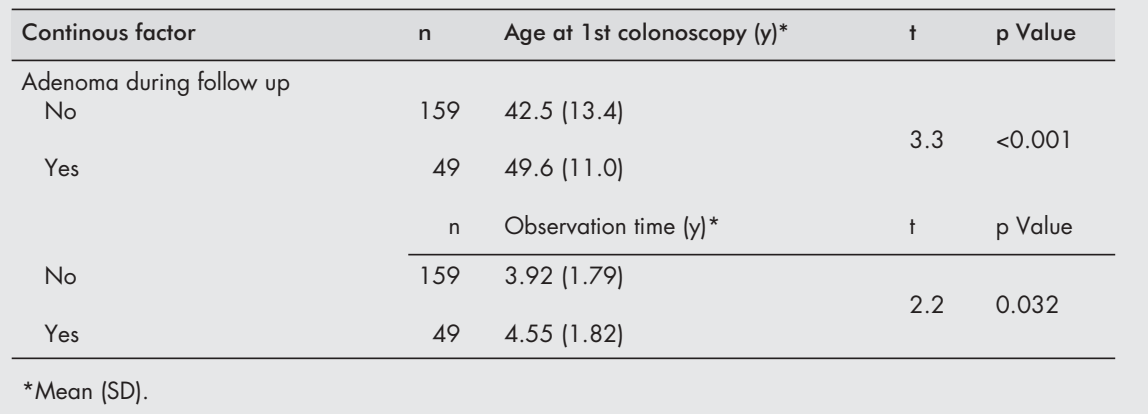


Table 9 Stepwise logistic regression analysis with respect to adenoma incidence (no/yes) during follow up

\begin{tabular}{llll}
\hline Factor & OR & $\mathrm{Cl}$ & $\mathrm{p}$ Value \\
\hline Adenoma at 1st colonoscopy & 2.56 & $1.10-5.93$ & 0.029 \\
Observation time (y) & 1.29 & $1.07-1.56$ & 0.008 \\
Age 10* & 1.55 & $1.18-2.03$ & 0.002 \\
Constant -4.44 & & & \\
\hline
\end{tabular}

Odds ratio (OR) and $95 \%$ confidence intervals (CI). Competing non-significant factors were sex and family classification: HNPCC and HERcrc.

Age 10*, age at 1 st colonoscopy with 10 year increment.

HNPCC, hereditary non-polyposis colorectal cancer; HCRC, cancer; HERcrc, HCRC and TCR.

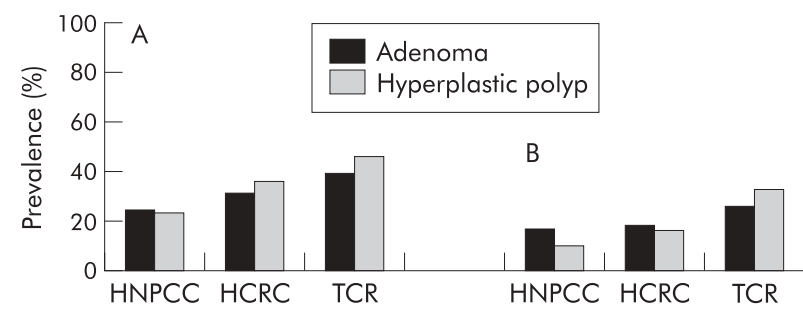

Figure 2 (A) Prevalence of ever having a hyperplastic polyp or an adenoma and (B) prevalence of having a hyperplastic polyp or an adenoma at first colonoscopy.

and two HNPCC gene carriers developed a metachronous colorectal cancer during surveillance.

\section{Correlation between adenomas and hyperplastic polyps in the risk population}

A positive correlation was found between the numbers of hyperplastic polyps and adenomas in the whole study population $(r=0.40, \mathrm{p}<0.001)$ (table 1$)$. This correlation was also statistically significant during follow up. The correlation between adenomas and hyperplastic polyps was similar in the three groups (HNPCC, HCRC, and TCR) (table 2) as well as among patients with previous colorectal cancer and known mutation carriers. There was also a significant correlation of detecting a lesion at subsequent colonoscopies during follow up if a positive finding was observed at first colonoscopy $(\mathrm{p}<0.001)$ (table 3$)$. The group with positive findings at first colonoscopy had a shorter observation time compared with the group without lesions at first colonoscopy. Correcting for the different observation times improved the correlation (table 3).

\section{Incidence of hyperplastic polyps and adenomas increased with age in all family types}

The risk of detecting new hyperplastic polyps or adenomas increased in all age groups when there was a positive finding at first colonoscopy (fig 1), and the probability increased with a longer observation time. When calculating the incidence (number of polyps found during follow up, excluding all polyps found at first colonoscopy) during follow up it was obvious that a finding of a hyperplastic polyp at first colonoscopy increased the risk of detecting new hyperplastic polyps at follow up (odds ratio (OR) 5.41) (tables 4-6). An augmented risk of detecting new hyperplastic polyps was also observed with increased age at first colonoscopy (OR 1.50) and observation time (OR 1.23) (tables 4-6). The given ORs are multiple. There were similar findings regarding adenomas, with statistically significant numbers for adenoma at first colonoscopy, age at first colonoscopy, and observation time (tables 7-9). Competing non-significant factors in both analysis of hyperplastic polyps and adenomas were sex and family classification. Including all colonoscopies, 14\% of individuals with a hyperplastic polyp at first colonoscopy developed subsequent adenomas compared with $17 \%$ of individuals without hyperplastic polyps at first colonoscopy $(p=0.617)$. In contrast, $35 \%$ of individuals with adenomas at first colonoscopy developed hyperplastic polyps compared with $20 \%$ of individuals with no adenomas at first colonoscopy $(\mathrm{p}=0.020)$ (data not shown).

\section{Prevalence of hyperplastic polyps and adenomas varied between family types}

There was an overall statistically significant difference in the prevalence of ever having a hyperplastic polyp and prevalence of having a hyperplastic polyp at first colonoscopy between the three family groups (HNPCC, HCRC, and TCR) (table 10, fig 2). There was also a statistically significant difference of ever having a hyperplastic polyp between the HNPCC and TCR groups $(p=0.004)$ and a borderline statistically significant difference between the HCRC and HNPCC groups $(\mathrm{p}=0.062)$. The same tendency was seen for the prevalence of adenomas

Table 10 Number and prevalence of adenomas and hyperplastic polyps

\begin{tabular}{|c|c|c|c|c|}
\hline & HNPCC & HCRC & TCR & $\mathrm{p}$ Value \\
\hline No of patients & 108 & 127 & 64 & \\
\hline No of adenomas & 48 & 87 & 51 & \\
\hline Mean age at first colonoscopy & 41.4 & 45.6 & 49.2 & \\
\hline Mean age at last colonoscopy & 44.3 & 49.0 & 51.1 & \\
\hline Subjects with adenomas & 26 & 39 & 25 & \\
\hline No of adenomas (adenomas/individual)* & $0.44(0.95)$ & $0.69(1.63)$ & $0.80(1.29)$ & $0.200 t$ \\
\hline Mean No of adenomas/individual with adenoma & 1.85 & 2.23 & 2.04 & \\
\hline Prevalence: adenoma at first colonoscopy (\%) & $16.0 \quad(n=17)$ & $17.3(n=22)$ & $25.0(n=16)$ & $0.618 \neq$ \\
\hline Prevalence: ever having an adenoma (\%) & $24.1 \quad(n=26)$ & $31.0 \quad(n=39)$ & $39.1 \quad(n=25)$ & $0.115 \ddagger$ \\
\hline No of hyperplastic polyps & 64 & 139 & 89 & \\
\hline Subjects with hyperplastic polyps & 25 & 44 & 29 & \\
\hline $\begin{array}{l}\text { No of hyperplastic polyps (hyperplastic } \\
\text { polyps/individual)* }\end{array}$ & $0.59(1.37)$ & $1.09(2.13)$ & $1.39(2.49)$ & $0.027 t$ \\
\hline $\begin{array}{l}\text { Mean No of hyperplastic polyps/individual with } \\
\text { hyperplastic polyps }\end{array}$ & 2.56 & 3.16 & 3.07 & \\
\hline $\begin{array}{l}\text { Prevalence: hyperplastic polyp at first colonoscopy } \\
(\%)\end{array}$ & $9.3 \quad(n=10)$ & $15.7 \quad(n=20)$ & $31.3(n=20)$ & $0.001 \neq$ \\
\hline Prevalence: ever having a hyperplastic polyp (\%) & $23.1 \quad(n=25)$ & $35.0 \quad(n=44)$ & $45.3(n=29)$ & $0.010 \ddagger$ \\
\hline
\end{tabular}

*Mean (SD).

tOne way analysis of variance.

$\neq \chi^{2}$ test

HNPCC, hereditary non-polyposis colorectal cancer; HCRC, hereditary colorectal cancer; TCR, two close relatives with colorectal cancer. 
Table 11 Multivariate linear regression analyses with respect to number of hyperplastic polyps (prevalence at last observation ( $\mathrm{n}=299$ ); regression coefficient (beta))

\begin{tabular}{|c|c|c|c|c|}
\hline Factor & Beta & SE & $t$ & $\mathrm{p}$ Value \\
\hline Age at last colonoscopy* & 0.315 & 0.088 & 3.6 & $<0.001$ \\
\hline Family classification & 0.416 & 0.243 & 1.7 & 0.088 \\
\hline $\begin{array}{l}\text { Sex } \\
\text { Constant }-1.358\end{array}$ & 0.096 & 0.233 & 0.4 & 0.683 \\
\hline
\end{tabular}

*Age per 10 year increment.

Family classification: 1=HNPCC, 2=HERcrc

Competing non-significant statistical factors were sex and family classification

Table 12 Multivariate linear regression analysis with respect to number of adenomas (prevalence at last observation ( $n=299)$; regression coefficient (beta))

\begin{tabular}{llllr}
\hline Factor & Beta & SE & $\dagger$ & $\mathrm{p}$ Value \\
\hline Age at last colonoscopy* & 0.247 & 0.059 & 4.2 & $<0.001$ \\
Family classification & 0.168 & 0.164 & 1.0 & 0.307 \\
Sex & -0.094 & 0.157 & -0.6 & 0.551 \\
Constant-0.681 & & & & \\
\hline
\end{tabular}

*Age per 10 year increment.

Family classification: $1=$ HNPCC, $2=$ HERcrc

Competing non-significant statistical factors were sex and family classification.

(table 10, fig 2). In patients with hyperplastic polyps or adenomas (most likely to be at highest risk for colorectal cancer), there was no statistically significant difference in the frequency of lesions between the different family types. However, there was a trend for subjects in the HCRC and TCR groups to have more hyperplastic polyps and adenomas than subjects in the HNPCC groups (table 10). There was a statistically significant positive correlation between age at last colonoscopy and total number of hyperplastic polyps found during the observation time (table 11). A similar finding was observed for adenomas (table 12). No statistically significant correlation was found when the same analyses for sex and family groups were performed (data not shown).

\section{Prevalence of adenomas and hyperplastic polyps among individuals with colorectal cancer}

Among the 24 subjects with previous colorectal cancer tumours, the prevalence of ever having an adenoma was $38 \%$ and the prevalence of ever having a hyperplastic polyp was $33 \%$. Among the 20 positive mutation carriers in the HNPCC group with a history of colorectal cancer, there were $40 \%$ who reported ever having an adenoma and 30\% a hyperplastic polyp compared with HNPCC individuals without a history of colorectal cancer with detection of $20 \%$ with an adenoma and $22 \%$ with a hyperplastic polyp. These differences were not statistically significant (data not shown).

\section{Distribution and size}

Hyperplastic polyps were primarily distributed in the distal colon

In the whole study population, $72 \%$ of hyperplastic polyps were protruded and $28 \%$ were non-protruding. Hyperplastic polyps were primarily distributed in the distal colon in all three groups and the predominance for distal distribution was statistically significant in HNPCC $(p=0.005)$ and HCRC $(p=0.023)$ but not in TCR $(p=0.191)$. Adenomas were evenly distributed (fig 3). The vast majority ( $77 \%$ of adenomas and $80 \%$ of hyperplastic polyps) were $1-5 \mathrm{~mm}$. The size of the hyperplastic polyps was not related to recurrence although the
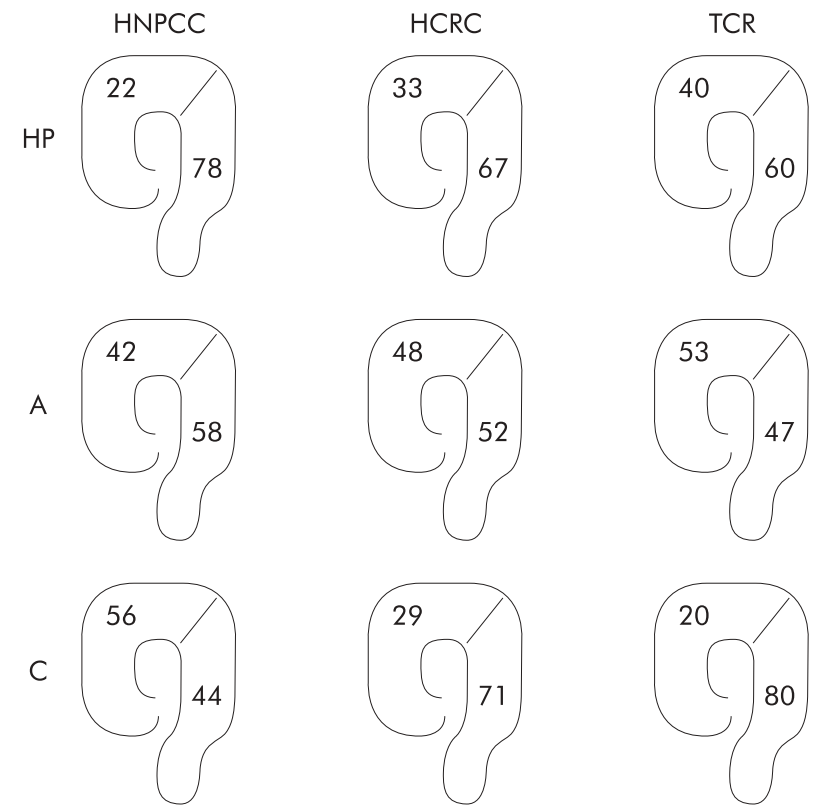

Figure 3 Localisation of hyperplastic polyps (HP), adenomas (A) and carcinomas $(C)$ in the three family types (HNPCC, hereditary non-polyposis colorectal cancer; HCRC, hereditary colorectal cancer; TCR, two close relatives with colorectal cancer). Distributions are given as percentages in the proximal and distal colon.

numbers were small (24 hyperplastic polyps $1-5 \mathrm{~mm}$, five hyperplastic polyps $5-10 \mathrm{~mm}$ ). There was a trend for an increased risk of recurrence among larger $(5->10 \mathrm{~mm})$ adenomas, but this was not statistically significant due to the small number of lesions ( 22 adenomas $1-5 \mathrm{~mm}$, nine adenomas 5-10 mm, and one adenoma $>10 \mathrm{~mm}$ ) (data not shown).

\section{DISCUSSION}

We found that there was a comparatively strong correlation between hyperplastic polyps and adenomas in subjects with an increased risk of colorectal cancer due to family history. An earlier study also found an association between adenomas and hyperplastic polyps. These results were however observed in a symptomatic population group. ${ }^{26}$ Detection of either a hyperplastic polyp or an adenoma at the first colonoscopy could predict findings of new hyperplastic polyps and/or adenomas in the colon during subsequent surveillance. An adenoma in an individual is a well recognised marker for an increased risk of colorectal cancer while a hyperplastic polyp is not considered to be a premalignant lesion. The results of our correlation analyses suggest that hyperplastic polyps or adenomas found at surveillance could be useful markers in identifying individuals who have the highest risk of colorectal cancer. A previous study on adenomas in HNPCC supports these findings ${ }^{27}$ Lanspa et al showed that new adenomas were detected at subsequent colonoscopies in $86 \%$ of HNPCC patients with adenomas at the first colonoscopy. ${ }^{27}$ This was also found in our study population (tables 7-9). However, only seven adenomas were found after 50 findings of a hyperplastic polyp at first colonoscopy. This suggests that hyperplastic polyps are less good predictors of future adenomas. Among positive mutation carriers who had a history of colorectal cancer, $40 \%$ reported ever having an adenoma and 30\% ever having a hyperplastic polyp. The prevalence of ever having an adenoma or a hyperplastic polyp in the HNPCC group (known and unknown mutation status) was $24.1 \%$ and $23.1 \%$, respectively (tables 11, 12), and most adenomas and hyperplastic polyps were found in positive mutation carriers with a history of colorectal cancer. The reason for finding more adenomas and hyperplastic polyps in subjects at risk might be that these 
individuals have an increased tendency towards proliferation in the colon mucosa. Review of the literature reveals numerous studies discussing the significance of hyperplastic polyps in the general population. A higher prevalence of hyperplastic polyps has been found in patients with colorectal cancer compared with those without colorectal cancer. ${ }^{19}$ One study found an increased probability of neoplastic polyps in the same segment of the colon as the hyperplastic lesion. ${ }^{28}$ These findings support the view of an association between hyperplastic polyps and colorectal cancer. The overall prevalence of hyperplastic polyps in the general population has been reported as $7-40 \%$ in autopsy studies $^{35}$ and the prevalence of hyperplastic polyps in an average risk nonsymptomatic population $>50$ years of age is $20-40 \% .^{35}$ Thus there is wide variation in the prevalence of hyperplastic polyps in different studies. The prevalence of ever having a hyperplastic polyp in our study group was $33 \%$, with a wide variation (range $23.1 \%$ in HNPCC and $45.3 \%$ in TCR) (table 10). Future studies will show whether individuals with familial colorectal cancer have more hyperplastic polyps than the general population.

We tried to elucidate different phenotypes, representing different genetic backgrounds, in HNPCC and the two other risk groups, HCRC and TCR. We found that the prevalence of ever having and having a hyperplastic polyp at first colonoscopy was more common in HCRC and TCR compared with HNPCC. This is surprising as the estimated mutation carrier frequency was higher in the HNPCC group compared with the two other groups where it was not possible for mutation carriers to be identified. The HCRC and TCR groups also had a higher incidence of lesions than the HNPCC group, although this was not significant due to the limited number of samples. Similarly, the numbers of hyperplastic polyps and adenomas per individual were slightly higher for HCRC and TCR compared with HNPCC, although the numbers did not differ significantly between the groups (table 10). In our recent study ${ }^{18}$ there was a significant difference between the three groups (HNPCC, HCRC, and TCR), with the highest number of adenomas per individual found in TCR. That study prompted us to screen all HCRC and TCR families to find germline mutations possibly associated with a weak phenotype and attenuated familial adenomatous polyposis (AFAP) (unpublished results). One of the subjects with numerous adenomas in the TCR group has since been diagnosed with a germline APC mutation and AFAP. This subject was not included in our study and the number of adenomas in the TCR families decreased.

Recent studies indicate that right sided large hyperplastic polyps could give rise to sporadic colorectal MSI positive cancers $^{29}$ and patients with numerous hyperplastic polyps ("hyperplastic polyposis syndrome") have a predisposition to develop right sided MSI high colon carcinomas. ${ }^{30}{ }^{31}$ In our study, however, hyperplastic polyps were predominantly distributed in the distal part of the colon, mostly pronounced in the HNPCC group, and hyperplastic polyps are generally considered not to have any malignant potential or indication of risk for metachronous cancer. ${ }^{32}$ In contrast, adenomas are generally considered premalignant and in our study were equally distributed in all three family types, suggesting that colorectal cancer arises evenly in the colon in all three family types. Carcinomas were fairly evenly distributed in HNPCC, but were clearly more distal in HCRC and TCR (fig 3). Hence all adenomas in HNPCC seem to have a high cancer risk while it is possible that in HCRC and TCR distal adenomas may confer a higher cancer risk than proximal adenomas.

In conclusion, we have reported a correlation between hyperplastic polyps and adenomas in individuals at risk of developing colorectal cancer. Hyperplastic polyps as well as adenomas may identify individuals with a high risk of colorectal cancer. By using the formula for logistic regression it was possible to calculate the probability of future adenomas

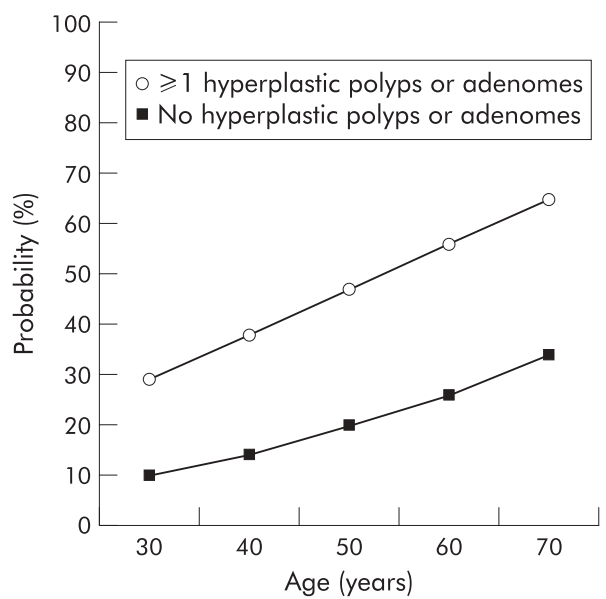

Figure 4 Model based fitted for the probability of detecting a hyperplastic polyp or an adenoma at subsequent colonoscopy (three years) depending on positive or negative findings at the first colonoscopy.

and hyperplastic polyps in risk individuals (fig 4). This information is important and could be used when tailoring surveillance programmes in familial colorectal cancer. The significance of the hyperplastic polyp is still an enigma but our results indicate that the hyperplastic polyp is worth studying further and it is better to alert than to neglect when observing this "innocent" polyp in high risk individuals.

\section{ACKNOWLEDGEMENT}

Grant support was provided by the Swedish Cancer Society, the Karolinska Institutet, the Karolinska Hospital, the Stockholm County Council, and the Cancer Foundation in Stockholm

\section{Authors' affiliations}

A Liljegren, Department of Clinical Genetics, Karolinska Hospital, and Department of Clinical Oncology, Danderyds Hospital, Stockholm, Sweden

A Lindblom, Department of Clinical Genetics, Karolinska Hospital, Stockholm, Sweden

S Rotstein, Department of Clinical Oncology, Danderyds Hospital, Stockholm, Sweden

B Nilsson, Institution of Oncology and Pathology, Unit of Cancer Epidemiology, Radiumhemmet, Karolinska Hospital, Stockholm, Sweden C Rubio, Department of Oncology and Pathology, Karolinska Hospital Stockholm, Sweden

E Jaramillo, Department of Gastroenterology, Karolinska Hospital, Stockholm, Sweden

\section{REFERENCES}

1 Muto T, Bussey HJ, Morson BC. The evolution of cancer of the colon and rectum. Cancer 1975:36:2251-70.

2 Järvinen $\mathrm{HJ}$, Aarnio M, Mustonen $\mathrm{H}$, et al. Controlled 15-year trial on screening for colorectal cancer in families with hereditary nonpolyposis colorectal cancer. Gastroenterology 2000:118:829-34.

3 Williams AR, Balasooriya BA, Day DW. Polyps and cancer of the large bowel: a necropsy study in Liverpool. Gut 1982:23:835-42. 4 Spiut H, Estrada RG. The significance of epithelial polyps of the large bowel. Pathol Annu 1977;12:147-70.

5 Vatn $\mathbf{M H}$, Stalsberg $\mathrm{H}$. The prevalence of polyps of the large intestine in Oslo: an autopsy study. Cancer 1982;49:819-25.

6 Croizet O, Moreau J, Arany Y, et al. Follow-up of patients with hyperplastic polyps of the large bowel. Gastrointest Endosc 1997;46:119-23

7 Huang EH, Whelan RL, Gleason NR, et al. Increased incidence of colorectal adenomas in follow-up evaluation of patients with newly diagnosed hyperplastic polyps. Surg Endosc 2001;15:646-8.

8 Fraser GM, Niv Y. Hyperplastic polyp and colonic neoplasia. Is there an association? J Clin Gastroenterol 1993;16:278-80.

9 Cancer Incidence in Sweden. The National Board of Health and Welfare Centre for Epidemiology, 1998.

10 Fuchs CS, Giovannucci EL, Colditz GA, et al. A prospective study of family history and the risk of colorectal cancer. N Engl J Med 1994:331:1669-74.

11 Lovett E. Family studies in cancer of the colon and rectum. Br J Surg 1976;63:13-18. 
12 Aaltonen LA. Hereditary intestinal cancer. Semin Cancer Biol 2000:10:289-98.

13 Leach FS, Nicholaides NC, Papadopoulos N, et al. Mutations of a mutS homolog in hereditary nonpolyposis colorectal cancer. Cell 1993;75:1215-25.

14 Bronner CE, Baker SM, Morrison PT, et al. Mutation in the DNA mismatch repair gene homologue $\mathrm{hMLHl}$ is associated with hereditary non-polyposis colon cancer. Nature 1994;368:258-61.

15 Miyaki M, Konishi M, Tanaka K, et al. Germline mutation of MSH6 as the cause of hereditary nonpolyposis colorectal cancer. Nat Genet 1997:17:271-2.

16 Lynch HT, de la Chapelle A. Genetic susceptibility to non-polyposis colorectal cancer. J Med Genet 1999;36:801-18.

17 Vasen HF, Watson P, Mecklin JP, et al. New clinical criteria for hereditary nonpolyposis colorectal cancer (HNPCC, Lynch syndrome) proposed by the International Collaborative group on HNPCC. Gastroenterology 1999;116:1453-6.

18 Lindgren G, Liljegren A, Jaramillo $E$, et al. Adenoma prevalence and cancer risk in familial non-polyposis colorectal cancer Gut 2002;50:228-34

19 Eide TJ. Prevalence and morphological features of adenomas of the large intestine in individuals with and without colorectal carcinoma. Histopathology 1986;10:111-18.

20 Rubio CA, Jaramillo $E$, Lindblom A, et al. Classification of colorectal polyps: guidelines for the endoscopist. Endoscopy 2002;34:226-36

21 Rubio CA, Rodensjo M. Flat serrated adenomas and flat tubular adenomas of the colorectal mucosa; differences in the pattern of cell proliferation. Jpn J Cancer Res 1995:86:756-60.

22 Liu T, Wahlberg S, Burek E, et al. Microsatellite instability as a predictor of a mutation in a DNA mismatch repair gene familial colorectal cancer. Genes Chromosomes Cancer 2000;27:17-25.
23 Boland CR, Thibodeau SN, Hamilton SR, et al. A National Cancer Institute Workshop on Microsatellite Instability for cancer detection and familial predisposition: development of international criteria for the determination of microsatellite instability in colorectal cancer. Cancer Res 1998;58:5248-57

24 Wahlberg S, Liu T, Lindblom $\mathrm{P}$, et al. Various mutation screening techniques in the DNA mismatch repair genes $\mathrm{hMSH} 2$ and $\mathrm{hMLH} 1$. Genet Test 1999;3:259-64.

25 Huang J, Kuismanen SA, Liu T, et al. MSH6 and MSH3 are rarely involved in genetic predisposition to nonpolypotic colon cancer. Cancer Res 2001;61:1619-23.

26 Ansher AF, Lewis JH, Fleisher DE, et al. Hyperplastic colonic polyps as a marker for adenomatous colonic polyps. Am J Gastroenterol 1989:84:113-7.

27 Lanspa SJ, Lynch HT, Smyrk TC, et al. Colorectal adenomas in the Lynch syndromes. Results of a colonoscopy screening program. Gastroenterology 1990;98:1117-22.

28 Cappell MS, Forde KA. Spatial clustering of multiple hyperplastic, adenomatous, and malignant colonic polyps in individual patients. Dis Colon Rectum 1989;32:641-52.

29 Hawkins NJ, Ward RL. Sporadic colorectal cancers with microsatellite instability and their possible origin in hyperplastic polyps and serrated instability and their possible origin in hyperplastic

30 Rashid A, Houlihan PS, Booker S, et al. Phenotypic and molecular characteristics of hyperplastic polyposis. Gastroenterology 2000;119:323-32

31 Jass JR, lino H, Ruszkiewicz A, et al. Neoplastic progression occurs through mutator pathways in hyperplastic polyposis of the colorectum. Gut 2000:47:43-9.

32 Winawer SJ, Fletcher RH, Miller L, et al. Colorectal cancer screening clinical guidelines and rationale. Gastroenterology 1997;1 12:594-642. 